\title{
Data Structure Model on the Quality of Public Passenger Transport Services by Bus in Vietnam
}

\author{
Thi Hong Le Hoang Van Lam Hoang Thi Bich Hanh Chu \\ University of Transport Technology, Vietnam \\ Thi Thai An Nguyen Thi Bach Tuyet Vuong Thi Huyen Do \\ University of Transport Technology, Vietnam \\ Vu Hoang Nguyen \\ BaoViet Life, Vietnam \\ Manh Dung Tran \\ National Economics University, Vietnam
}

\begin{abstract}
The system of managing public passenger transport services (PPTS) by bus is a complex system, involving infrastructure, facilities, management and service communication activities between passengers and transport systems. In particular, quality information is the most important factor, providing necessary data for analysis, setting out measures to improve quality to meet the needs of passengers and meet the requirements of related parties. According to the peculiarity of the service, this study selects a database structure model to guide the process of computerizing the management of quality of PPTS by bus in urban areas in Vietnam. The results show that four database systems reflecting the quality information of the infrastructure, means of transport, transport operation and passenger service and each database system is structured by components that ensure proper implementation of QM process according to the continuous quality improvement cycle. The components of each database system are dispersed according to the scope of management to ensure the consistency for the quality management process and facilitate the collection, processing and distribution of information of related parties.
\end{abstract}

Keywords: Quality, transport services, public passengers, Vietnam.

DOI: $10.7176 / \mathrm{JESD} / 10-10-13$

Publication date:May $31^{\text {st }} 2019$

\section{Introduction}

Essentially, quality management (QM) is the process of designing, collecting and processing information related to the entire process of controlling the interaction between management apparatus and management objects in order to ensure product quality. This is a complex and costly process, requiring each production and business organization to build effective tools for collecting and processing information, ensuring timely information supply, reflecting fully and accurately product quality in the process of "production - supply - consumption" and saving costs. Public transport by bus is a complex service system consisting of many components that are closely related to the service supply chain, in which, infrastructure and operating traffic flow are under the management responsibility of the city government (People's Committee (PPC) and Department of Transport (DOT)); transport firms perform the task of operating vehicles and serving passengers. The hierarchical management of service constituents has a direct influence on the database design for the process of collecting and processing information on quality of PPTS of the whole service system.

The database structure model on the quality of PPTS has the nature of dispersing according to each component of the service system under the responsibility of the relevant management entities, in the direction of developing a distributed database model, service oriented software (SOA - Service Oriented Architecture) with stratified architecture includes: database, data retrieval applications, communication (connection layer) ), a set of program modules (service layers) and applications according to management processes (application layer) (Thomas, 2005). In particular, the development of cloud computing services will ensure the flexibility and efficiency for the process of designing, collecting and processing information on quality of public passenger transport services by bus of each city.

\section{Literature Review}

In major cities in Vietnam, the problem of traffic congestion and improving the quality of public passenger transport services (PPTS) pose an urgent task for city traffic management and transport businesses. The active participation of scientists and research organizations seeks to find a more effective solution both in terms of development policies and specific management measures. However, in-depth studies on the quality of PPTS by bus in the city are very limited in terms of the number and depth of theory. Few studies have mentioned some 
aspects or orientations to improve the quality of PPTS. Some research projects provide a principle scientific basis to guide the quality management, assessment of service quality in general and public PPTS in particular.

Hoang (2005) developed an appropriate quality management model (QCT) with a model of "Quality house" (applied to goods manufacturing enterprises) and "Quality tree" (applied to service firms) to providing a scientific basis for analyzing and building the quality management system of firms. The QCT model consists of 15 internal elements of three groups: (i) The fundamental elements that constitute the "house foundation" (quality house model) or "tree roots" (quality tree model); (ii) The main factors that constitute the "roof" (quality house model) or "trunk" (quality tree model) and (iii) core elements that create "pillars" (quality house model) or "tree canopy" (quality tree model), and analyze 10 external factors affecting business performance. However, the QCT model only provides a general principle to guide the research and design of the quality management system without mentioning a specific type of service.

In the research direction of seeking solutions to improve the efficiency of public passenger transport services, Nguyen (2014) mentioned some aspects of quality such as promptitude, safety and reliability, and convenience of public passenger transport services. The research used sociological survey tools to build mathematical models to assess the quality of public passenger transport services in 6 criteria (cost, access, safety, reliability, facilities and employees). The quality evaluation results are used as one of the factors to analyze and propose solutions to improve the efficiency of public passenger transport services by bus in Hanoi city.

Some studies analyzed the reasons why public passenger transport services (PPTS) are not really attractive to people and found that they related to transport network planning, thus proposing methods to develop bus journey evaluation criteria (Tu, 2014); studying to optimize the time of passenger trips by bus in the city by the O-D method to improve the quality of passenger service $(\mathrm{Tu}, 2015)$.

Nguyen (2009) studied the relationship between passenger satisfaction and the quality of PPTS by bus in the inner city routes of Ho Chi Minh city. The research used the sociological survey method, asking passengers to use buses of the inner city of Ho Chi Minh City according to the following criteria: the comfort of the vehicles, the service attitude of car driver team; stop-shelters and safety.

In May 2015, a group of experts from the Center for Urban Forecasting and Research (French Republic) coordinated with experts and traffic management agencies of Hanoi and Ho Chi Minh City to organize training programs to advise on the management and operation of public transport networks in cities in Vietnam. In particular, the experts proposed to assess the quality of PPTS by bus based on six criteria of customer relations, safety, punctuality, information, and cleanliness (Huynh \& Charles, 2015). The program raised recommendations on necessary solutions to optimize the transportation network rather than improve the quality of transport services. This view is based on the subjective perspective of macro managers to consider the fundamental elements of PPTS as the infrastructure system.

In Vietnamese cities, bus transportation is a type of public transport that plays an important role in addressing traffic congestion and bringing practical benefits to people. Solutions to improve the efficiency of public passenger transport services in general and bus passenger transport in particular have been mentioned in development policies and action programs of all levels and sectors of the city government. Because the infrastructure has not been developed yet, most of recommendations which were studied and implemented are derived from the viewpoint of state management, mainly focusing on the objective of improving the infrastructure quality of the transport system. In theory, the in-depth studies only perform on some aspects of the quality of PPTS by bus but have not systematically studied the determinants related to service quality, thus propose appropriate management measures. Hence, on the basis of certain infrastructure conditions, it is necessary to derive from the needs, expectations of passengers, the ability to meet, the level of readiness and determination to implement the quality objectives of firms to have effective, feasible and suitable recommendations with conditions of exploiting PPTS by bus in each. At the same time, there should be consistency and synchronization between development policies, state management mechanisms and management organization of firms.

\section{Data structure model on the quality of public passenger transport service by bus}

\subsection{Quality relationship between service elements and output quality of PPTS by bus}

PPTS by bus is a form of transportation using cars to transport passengers on fixed routes of a city, operating according to operating charts and prescribed rates to satisfy daily travel needs of city people. The system of PPTS by bus consists of four basic management modules on infrastructure, means of transport, transport management and administration organizations and passenger service activities. According to the system structure, the quality management of service components has a certain influence on the output quality of the transport service. The level of influence of each factor is assessed on the basis of analyzing internal relations between service management modules and through feedback from passengers.

There are quality relations in the interactive chain of transport service delivery process between service elements and quality of service output provided to passengers. The output quality of each service element can be both input to other factors, while reflecting the quality of output services provided to passengers. The quality of 
infrastructure ensures the technical facilities and conditions for the management and operation of transport and organization of passenger service and at the same time affects the selection and operation of vehicles carriage. The quality of means of transport ensures the conditions for the organization and operation and service of passengers during the transport process. At the same time, the quality of means of transport also reflects the quality of the service output in terms of safety, convenience, comfort and sanitary conditions for passengers.

On the basis of technical conditions of infrastructure and the quality of means of transport, the organization and management of transport operations will ensure the conditions for organization of passenger service at the beginning and the end, and at the same time will determine the quality of service provided passengers with fast, safe, reliable and convenient service. With the condition of infrastructure, means of transport and transport operation, passenger service will ensure convenience, comfort, security and hygiene for the quality of the output provided to passengers in the whole transport process. Thus, the quality of output services provided to passengers is the result of a series of multiplication and interaction between the components of the service system together and interaction with passengers. This is an important basis to form the database structure to comprehensively reflect the quality of public passenger transport service by bus.

Quality of public passenger transport services

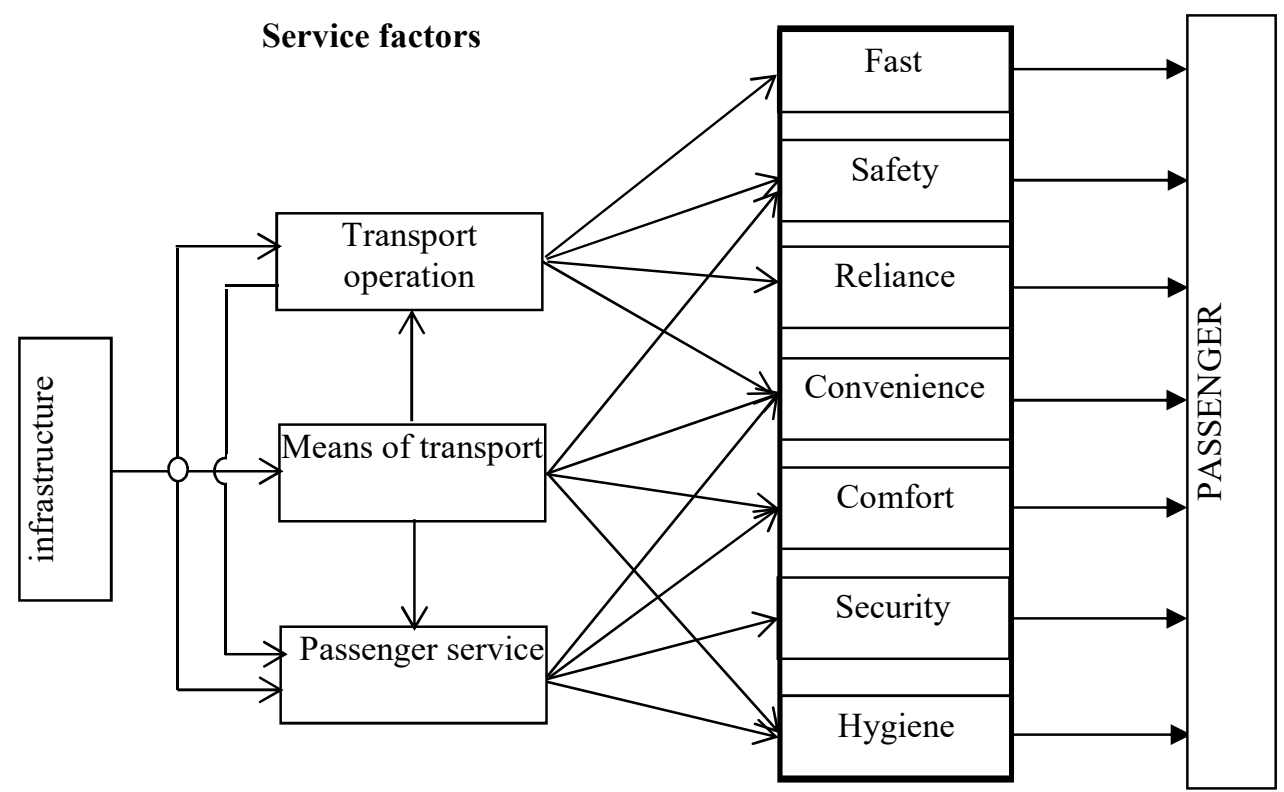

Figure 1. Quality relationship between elements of public passenger transport service by bus

\subsection{Database structure model on the quality of public passenger transport service by bus}

Quality management of PPTS by bus in urban areas in Vietnam operated according to the responsibility decentralization model between People's Committee, Department of Transportation and Transport firms for each component of service. In particular, the People's Committee and the Department of Transportation plans strategies and ensures the legal framework for quality management, infrastructure, means of transport, executive management and policies that support transport operation; Transport firms are mainly responsible for quality management of means of transport, operating organizations and passenger service (Le, 2016). The levels of responsibility for quality management of PPTS by bus in the context of Vietnam is illustrated in Table 1 below:

Table 1. Level of responsibility for quality management of PPTS by bus

\begin{tabular}{clccc}
\hline \multirow{2}{*}{ No } & Service factors & \multicolumn{3}{c}{ Management levels } \\
\cline { 3 - 5 } & Infrastructure & City People's & $\begin{array}{c}\text { Department of } \\
\text { Committee }\end{array}$ & Transport \\
\hline 1 & Means of transport & Low & Medium & Low \\
2 & Transport operation & Low & Medium & High \\
3 & Passenger service & Low & High & Medium \\
4 & Medium & High \\
\hline
\end{tabular}

According to management decentralization, information reflecting the quality of each element of the service system will be collected, processed and stored to serve the management of each related parties according to the total management process of service system. The quality management process is analyzed into 7 functions under the responsibility of the People's Committee, Department of Transportation (DOT) and Transport firms (Table 2) 
and operated in a continuous quality improvement cycle (Figure 2).

Table 2: Quality management function of PPTS by bus

\begin{tabular}{|c|c|c|}
\hline Signs & Name of function & $\begin{array}{l}\text { Management } \\
\text { responsibility }\end{array}$ \\
\hline $\mathrm{C} 1$ & Development strategies planning & PPC, DOT \\
\hline $\mathrm{C} 2$ & Quality goals planning & DOT, Transport firms \\
\hline $\mathrm{C} 3$ & $\begin{array}{l}\text { Developing quality programs (infrastructure, transport means, operating } \\
\text { transport, passenger services) }\end{array}$ & DOT, Transport firms \\
\hline $\mathrm{C} 4$ & $\begin{array}{l}\text { Implementation of quality programs (infrastructure, means of transport, } \\
\text { operating transport, passenger services) }\end{array}$ & DOT, Transport firms \\
\hline $\mathrm{C} 5$ & External quality assessment of PPTS by bus & Transport firms \\
\hline C6 & Organization of internal quality assessment & DOT, Transport firms \\
\hline $\mathrm{C} 7$ & Analyzing and proposing improvement measures & DOT, Transport firms \\
\hline \multicolumn{3}{|c|}{$\begin{array}{l}\text { In order to ensure the process of collecting, processing, storing information, the database system is analyzed } \\
\text { rding to the quality management relations of service elements and the quality of the output of services provided } \\
\text { assengers. According to the quality management cycle, the database structure model of quality of PPTS by bus } \\
\text { udes } 4 \text { databases of infrastructure (D1), transport operation (D2), means of transportation (D3) and passenger } \\
\text { ices (D4). Each database system is analyzed into data modules according to the quality management cycle, } \\
\text { uding: quality objectives (1), quality plans (2), implementation of quality plans (3), quality measurement (4) } \\
\text { analysis, quality improvement (5). The process of collecting and processing quality information of PPTS } \\
\text { ows the continuous management cycle of quality improvement with two lines of information: control flow, }\end{array}$} \\
\hline
\end{tabular}

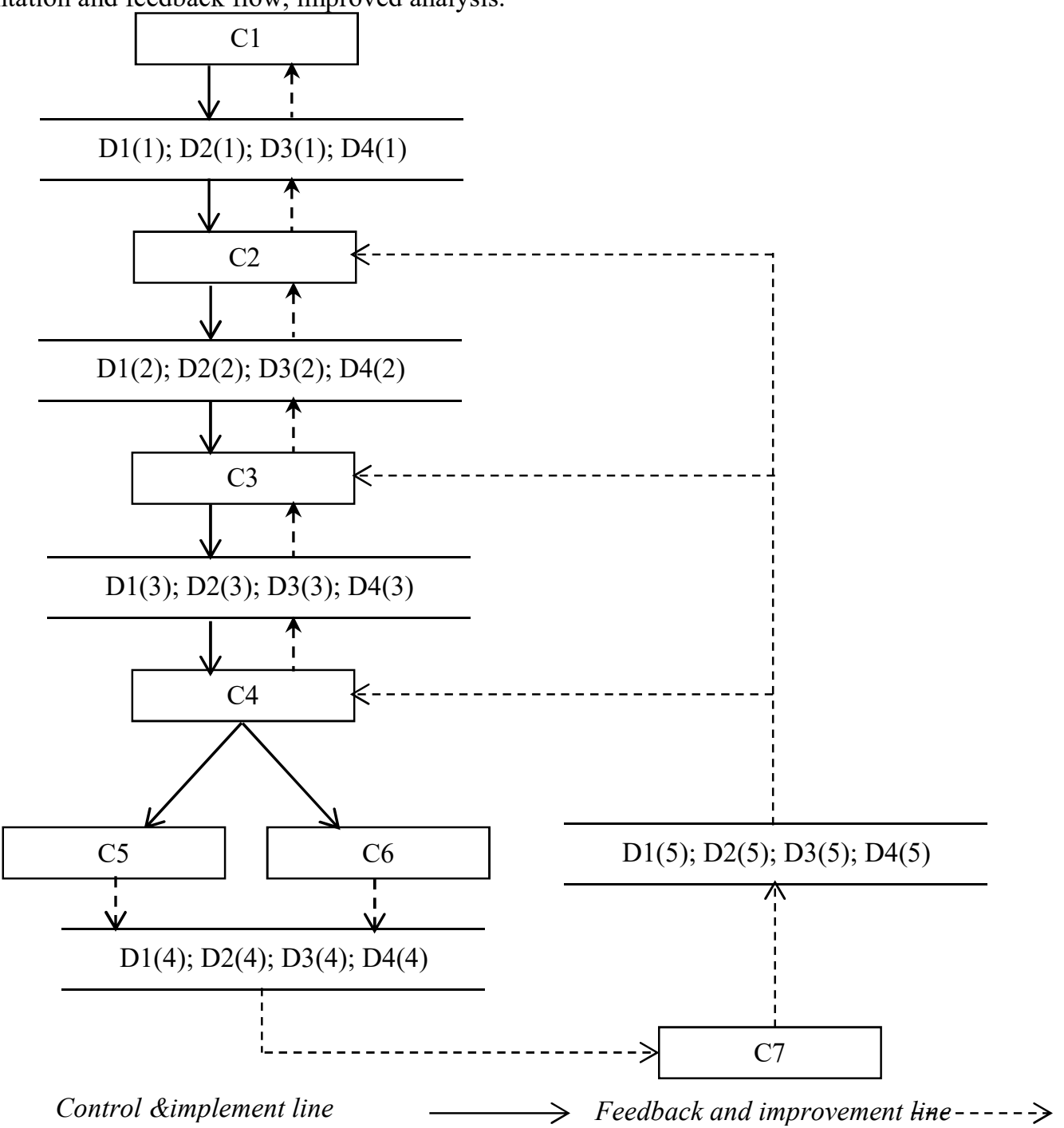

Figure 2. Information processing cycle under the process of quality management of PPTS by bus 


\section{Research Results}

The quality of public bus passenger transport service in Vietnam is rated quite well by passengers. The level of responsiveness to safety, convenience, security and hygiene is $65 \%$ higher than the highest quality level. The rapidity and reliability are still low. The satisfaction level of passengers on walking time, the waiting time at the bus stops was lower than the satisfaction level of passengers on the bus during transportation. Although the walking time depends on the location of the departure and destination for each passenger, the evaluation results partly explain the reasonable level of the route and bus stop network arrangement. The waiting time of passengers has not met the expectations of passengers.

The system of managing public passenger transport services (PPTS) by bus is a complex system. So the database system of quality of PPTS by buses is analyzed according to four database systems reflecting the quality information of the infrastructure, means of transport, transport operation and passenger service. At the same time, each database system is structured by components that ensure proper implementation of QM process according to the continuous quality improvement cycle. The components of each database system are dispersed according to the scope of management to ensure the consistency for the quality management process and facilitate the collection, processing and distribution of information of related parties (People's Committee, Department of Transportation and Transport firms). In order to implement the model, it is necessary to study the detailed design of the data structure on the basis of analyzing the properties that reflect the quality, assessment criteria and data coding requirements for each quality element of PPTS by bus. Then, depending on the mining conditions of each city to study and analyze management functions and build database systems accordingly.

In order to have good data structure model on the quality of public passenger transport services by the means of buses in the context of Vietnam, related parties should work together closely and share data and information frequently as well as feedback of clients (passengers). Based on the feedback of passengers on the buses, information and data should be shared and related parties such as City People's Committee, Department of Transport, and Transport firms discuss and find out good solutions for overcoming the weaknesses of the transport services by bus. So in the future, in the context of Vietnam, the structure model of information management and the satisfactions from passengers will be better.

\section{References}

Hoang, M. T. (2005), QCT: Appropriate quality management method for Vietnamese firms, Science and Technology Publishing House.

Hoang, T. H. L. (2016), Research to improve the quality of public passenger transport services by bus in Hanoi city, $\mathrm{PhD}$ Thesis, University of Transport and Communications, Vietnam.

Huynh, H. D., \& Charles, S. (2015), Managing and operating public transport networks, Urban Research and Forecast Center (PADDI).

Nguyen, H. T. (1999), Measures to improve the quality of car passenger transport services, PhD Thesis, National Economics University, Vietnam.

Nguyen, Q. T. (2009), The relationship between passenger satisfaction and the quality of public passenger transport services by buses in the inner routes of Ho Chi Minh city. Journal of Development Economics, 226, 17-25.

Nguyen, T. H. M. (2014), Improving the operational efficiency of public passenger transport systems in urban areas, $\mathrm{PhD}$ Thesis, University of Transport, Vietnam.

Thomas, E. (2005), Service-Oriented Architecture: Concepts, Technology, and Design, Text printed in United States on recycled paper at R.R. Donnelley in Crawfordsville, Indiana, ISBN 0-13-185858-0.

Tu, S. S. (2014), Method of developing standards for evaluating bus journeys in the city.

Tu, S. S. (2015), Optimizing time of bus trip in the city by $O-D$ method.

Hanoi People's Committee (2013), Regulations on management, operation, exploitation and use of urban road system in Hanoi city, Decision No. 15/2013-QD-UBND dated May 9, 2013.

Hanoi People's Committee (2016), Approving the Organization and Operation Charter of Hanoi Transport Corporation, Decision No. 2573/2016/QD-UBND dated 25 May 2016. 